\title{
GonzÁlez Bustos, María Ángeles, Mujer y desarrollo sostenible en el medio rural
}

\author{
José Luis Domínguez Álvarez \\ Universidad de Salamanca (España) \\ ORCID: https://orcid.org/0000-0002-7623-8029 \\ jldoal@usal.es
}

\begin{abstract}
NOTA BIOGRÁFICA
Personal Investigador en Formación (FPU17/01088) del Área de Derecho Administrativo de la Universidad de Salamanca, especializado en el estudio de la protección de datos de carácter personal ante la (r)evolución digital, la modernización de las Administraciones públicas, el desarrollo rural sostenible y la España vaciada, así como en la implementación de políticas públicas de igualdad y lucha contra la violencia de género.
\end{abstract}

\section{RESUMEN}

Recensión del libro de GonzÁLEz Bustos, María Ángeles: Mujer y desarrollo sostenible en el medio rural, Atelier, $1 .^{a}$ edición, 2020, 166 págs.

\section{PALABRAS CLAVE}

Mujer; desarrollo rural sostenible; igualdad de género; Administración pública.

\begin{abstract}
Review of the book from González Bustos, María Ángeles: Mujer y desarrollo sostenible en el medio rural, Atelier, 1. ${ }^{\mathrm{a}}$ ed., 2020, $166 \mathrm{pp}$.
\end{abstract}

\section{KEYWORDS}

Women; sustainable rural development; gender equality; public administration.

El medio rural es un concepto difuso, de reciente aparición, creado para designar aquello que no es ciudad, y generalmente entendido como un conjunto heterogéneo de territorios vencidos, o más bien de territorios «de vencidos». En las últimas décadas las zonas rurales que pueblan la geografía española han visto como la (i)lógica economía de mercado y el capitalismo depredador de recursos naturales y generador de grandes desigualdades, unida a la apatía de buena parte del conjunto de las Administraciones públicas, propiciaban una sangría poblacional sin precedentes, disminuyendo significativamente los estándares de calidad de vida de quienes un día decidieron desarrollar, de forma loable, su proyecto vital en el medio rural, favoreciendo con ello el abandono y el olvido del territorio, con la consiguiente pérdida cultural, patrimonial y ambiental, entre otras muchas, que esto genera.

Sin embargo, la crisis socioeconómica provocada por la irrupción de la COVID-19 ha traído consigo un cambio de paradigma que puede arrojar un hálito de vida crucial para garantizar la pervivencia de estos territorios despoblados. Así, ha permitido, por un lado, poner de relieve la importancia capital de conservar la ruralidad, vertebrar el territorio y combatir el abandono de las áreas rurales despobladas; y por otro, vi- 
sibilizar el papel de la mujer rural, la cual constituye el principal agente para alcanzar el ansiado desarrollo rural sostenible. Estas premisas requieren necesariamente avanzar en el establecimiento de un tratamiento jurídico-administrativo del medio rural diferenciado, radicalmente opuesto al otorgado por los poderes públicos en las últimas décadas, lo que exige a su vez un estudio sosegado y mesurado de las particularidades y peculiaridades que componen la realidad rural.

Este es el espíritu que subyace en la monografía de la profesora González Bustos, "Mujer y desarrollo sostenible en el medio rural", un estudio preciso, innovador y de consulta obligada para quienes por pasión y vocación se dedican a la búsqueda incansable de soluciones tangibles encaminadas a dignificar la España rural. De las musas al teatro, de las ideas a la acción. Esta expresión refleja a la perfección la esencia misma de la citada obra, un estudio capaz de trasladar al lector a la realidad existencial propia de la España vacia(da), sumergiéndolo en un viaje profundo a través de los principales hitos normativos y de aquellas actuaciones administrativas conducentes a dotar de contenido material lo preceptuado en el artículo 9.2 de la Constitución española, o lo que es lo mismo, a mejorar el bienestar y la calidad de vida de las mujeres rurales, protagonistas indiscutibles de lo que ha dado en denominarse «Nueva Ruralidad»; y que encuentra su punto álgido en el establecimiento de una serie de propuestas concretas encaminadas a mejorar las condiciones de vida de las mujeres rurales como presupuesto indispensable para alcanzar el anhelado desarrollo rural sostenible.

Como hemos tenido la oportunidad de adelantar, el punto de partida lo constituye el análisis de la igualdad de género como principio vertebrador de las políticas públicas de desarrollo rural sostenible, al que la autora reserva el primer capítulo. Es en este epígrafe donde se consigna la importancia capital de las mujeres rurales -colectivo que solamente en España integra a 6 millones de personas, lo que representa el $49,15 \%$ de la población en las zonas rurales- para el fomento del desarrollo sostenible del medio rural y la pervivencia de los municipios que se localizan en este preciado entorno, las cuales se presentan como agentes indiscutibles de desarrollo y modernización de estos territorios.

Todo ello, sin perjuicio del preceptivo estudio de la situación sociodemográfica que atraviesan las mujeres rurales, sometidas desde antiguo a una doble discriminación derivada, por un lado, de su condición de mujer, y por otro, por desarrollar su proyecto vital en el territorio rural, un espacio caracterizado, generalmente, por la falta de oportunidades laborales, la existencia de unas infraestructuras y servicios públicos deficientes y unas menores oportunidades de desarrollo personal y profesional. A este análisis hay que sumar un prolífico estudio de los principales hitos normativos -internacionales, europeos, nacionales y autonómicos-, así como de las diferentes soluciones jurídico-administrativas que el poder público ha impulsado con la finalidad de alcanzar la igualdad de oportunidades entre mujeres y hombres en el medio rural. Con todo ello se obtiene una extraordinaria foto fija de la realidad objeto de estudio, lo que permite a la autora reseñar dos de las principales aportaciones de la obra.

Comienza por identificar pormenorizadamente las áreas de actuación prioritarias en las que el poder público debe intervenir con apremio, mediante la articulación de políticas públicas dirigidas preferentemente a promover la igualdad de género, el emprendimiento y las oportunidades laborales, la conciliación de la vida personal, familiar y laboral, la corresponsabilidad, así como al establecimiento de unos servicios e infraestructuras mínimos que permitan mejorar el bienestar y la calidad de vida de las mujeres rurales. Sentado lo anterior, la autora muy acertadamente centra sus esfuerzos en desvelar, a nuestro modo de ver, una de las más tristes realidades que se esconden tras la densa y burocrática prosa de las normas administrativas y que explican en gran medida el fracaso de las iniciativas públicas orientadas a promover la igualdad de género en su sentido más amplio: «todas las políticas públicas enfocadas a la mujer del medio rural parten de una misma premisa (genérica): "la mujer rural en sentido amplio", o lo que es lo mismo, las actuaciones de los poderes públicos poseen un enfoque general, sin tener en cuenta los diferentes condicionantes que de una manera u otra hacen que la mujer que vive en el ámbito rural tenga necesidades diferentes...».

Examinar las particularidades y singularidades del medio rural español y la conceptualización del desarrollo rural sostenible constituyen el segundo capítulo de la monografía, espacio en el que se advierten y enumeran las perniciosas consecuencias que la despoblación y el abandono del territorio genera desde la óptica económica, patrimonial, medioambiental y social, entre otras muchas.

Adicionalmente, se detalla el alcance que los diferentes instrumentos normativos y de planificación presentan desde el punto de vista del fomento del desarrollo sostenible del medio rural y su interrelación con la promoción de la igualdad de género. Para ello, la autora centra sus esfuerzos en analizar no solamente el texto articulado de la Ley 45/2007, de 13 de diciembre, para el desarrollo sostenible del medio rural, así como las referencias a la igualdad contenidas en el Programa de Desarrollo Rural Nacional 2014-2020, o 
los principales preceptos de la Ley 35/2011, de 4 de octubre, sobre titularidad compartida de explotaciones agrarias, poderoso instrumento normativo que ha visto como el transcurso del tiempo y su escasa efectividad desdibujaban su finalidad primordial.

De igual forma, en este pasaje se incorporan una serie de valiosas reflexiones acerca de la problemática específica y agravada que representa la violencia de género en las áreas rurales -destacando la especial vulnerabilidad de las mujeres rurales-, y se enumeran una serie de iniciativas novedosas resultado de la implementación del Real Decreto-ley 9/2018, de 3 de agosto, de medidas urgentes para el desarrollo del Pacto de Estado contra la Violencia de género en el medio rural y del fomento de la colaboración y cooperación entre las diferentes Administraciones públicas. Este es el caso de la «Red de municipios sin violencia de género» o el modelo autonómico «Objetivo Violencia Cero» de Castilla y León.

Por su parte, el capítulo tercero aglutina un conjunto ordenado -pensado y reposado- de propuestas tangibles destinadas a alcanzar la mejora de las condiciones de vida de las mujeres rurales, las cuales se presentan como una alternativa cierta para que las Administraciones públicas avancen en el cumplimiento del mandato legal establecido en los arts. 9.2 y 103.1 CE: la consecución de la igualdad material entre mujeres y hombres como vehículo para garantizar la satisfacción de los intereses generales.

En este sentido, la autora se detiene en el esbozo de una serie de medidas de acción positiva, que en mayor o menor grado adoptan la forma de políticas públicas orientadas, principalmente, a fomentar el acceso, la permanencia y la promoción de las mujeres rurales en el mercado laboral, impulsar el emprendimiento femenino, potenciar la conciliación y la corresponsabilidad en el medio rural, acometer mejoras en infraestructuras y servicios esenciales en los territorios rurales despoblados -prestando especial atención a las comunicaciones electrónicas y la digitalización-, así como a maximizar la participación de las mujeres en los órganos de toma de decisiones.

Finalmente, el capítulo cuarto centra su atención en clarificar el entramado institucional encargado de promover la igualdad efectiva entre mujeres y hombres en el medio rural, tarea que requiere, necesariamente, el reconocimiento de una pluralidad de actores implicados de diferente naturaleza. Ciertamente, la consecución de este acuciante objetivo exige la intervención de las Administraciones públicas (garantía institucional), el sector empresarial, los movimientos asociativos y la comunidad rural, entendida como sociedad civil en su conjunto.

Especial referencia merece el análisis de una serie de organismos especializados en la difícil misión de convertir la promoción de la igualdad de género en la piedra angular del desarrollo sostenible del medio rural, con el que se cierra la obra, y cuya actuación pasa inadvertida generalmente. Entre estos organismos especializados en materia de desarrollo rural y mujer se profundiza en el conocimiento de la Comisión Interministerial para el Medio Rural, el Consejo para el Medio Rural y la Mesa de Asociaciones de Desarrollo Rural, al tiempo que se destaca la labor primordial que las organizaciones y asociaciones de mujeres rurales desempeñan, ya que son estos movimientos asociativos los que en multitud de ocasiones garantizan la salvaguarda de los derechos y libertades fundamentales de las mujeres que habitan en la España rural.

Estas son las principales notas características de una obra capital que avanza en el tratamiento jurídicoadministrativa de una problemática, la de las áreas rurales despobladas, que ha pasado desapercibida durante demasiado tiempo ante la mirada indiferente del conjunto de las Administraciones públicas, lo que ha propiciado el incremento sustancial de la desigualdad entre el medio urbano y el territorio rural, la minoración constante de los derechos y libertades fundamentales de las personas que integran las comunidades rurales, y en última estancia, el abandono del territorio.

Representa, por tanto, una ventana de esperanza ante el imparable proceso de despoblación y envejecimiento que sufre el mundo rural, ofreciendo una reflexión académica, pero eminentemente práctica, acerca de los factores que deben revertirse para frenar la dinámica actual que está asolando las áreas rurales y devolver con ello el alma a los pueblos. 